\title{
THE DEVELOPMENT OF SOCIAL POLICIES IN HEALTH
}

\author{
Cristina TOMESCU ${ }^{1}$
}

DOI: $10.35782 / J C P P .2019 .3 .02$

\begin{abstract}
The article analyzes some characteristics of the nowadays development of health policies, referring to the phases of the process of elaboration of public policies in health, to the new public management and to some characteristics that limit the reform process such as incrementalism, uncertainty and limited rationality theory. Also, it talks about deciding systems with closed structures, or about the limited capacity of the policy to reform the institutions, the windows of opportunity or sectoriality of the bealth policies.
\end{abstract}

Key words: public policies, health, efficiency of the health system, elaboration of policies, features

\section{Introduction}

The health system is a complex administrative one, having a resistance to change. Also, it is a great consumer of resources, budget and private ones. Each system has advantages and disadvantages, but a limit of quality must be established by every state in the provision of services. From the perspective of social protection, the indicated way to improve the financial support is to increase the efficiency of the health system by reducing costs, but maintaining at the same levels the quantity and quality, prevent over-consumption of medical services and allocate enough resources for prevention programs, in order to reduce future expenditures. Comparisons between different countries' experiences based on the expense / results ratio can be a useful tool to look at the efficiency (Chisholm D., Evans D. B., 2010). The analyzes on the social equity of health policies can be focused either on fiscal, or on administrative policies, but also on benefits/outputs. Theories to explain health policies can refer to political culture, the abilities of public policies to respond to improving the state health and possible solutions to the problem; or how political power of organizations ensure policy changes. (Arcaya M. et al., 2015).

Policies are mainly action guides that have the legitimate authority to impose normative action. In a democracy, policies are made by elected officials along with advisers from the higher hierarchy of the administration. Every public policy has three elements: the

${ }^{1}$ Senior Researcher, Research Institute for Quality of Life, Romanian Academy, Romania; E-mail: crisdobos@yahoo.com 
definition of the problem, the goals that the policy aims to achieve, the tools by which they approach the problem and the goals that are achieved. Defining the problem is essential, because the problem must be stated, and indicators are a monitoring tool that governors work with. The cause of a problem is also important, the structural factors; if the causes of the problem are not known, it is difficult to solve it. (Bousagguet L. et al., 2009)

Defining a problem is also related to the goals of the policy, that can be general or specific. Health policy has a general purpose, to maintain and improve health. At this level of generality, there is almost no disagreement on the goals. To the level of details and more precise goals, they become subject of discussion related to the effectiveness that these goals can have in solving the problem. Sometimes, the problems are ambiguous, and the goals are not very clear. (Blum H.L., 1974)

The question arises how the problems appear on the public agenda and influence the public agenda, arising in the collective conscience. Are the real problems different from the problems reflected in the collective consciousness? Zamfir C. speaks of a cyclicality of the emergence of social problems. See the crisis caused by a problem that erupts in the media from times to times, showing the deficiencies of the healthcare system. The social problem analyzed has a peak, then it falls into disgrace from the point of view of the media. The problem persists, but it is socially cyclical awareness through mass media, and it becomes cyclical in the attention of the community. Are the social policy measures influenced by these eruptions at the level of collective consciousness? Could these eruptions open windows of opportunity to change? I shall talk further on, in the article, about these windows of opportunity and their characteristics.

It is for sure, that citizens expect the rulers to make smart decisions and these decisions be the result of a vision. But it is not always the case. Decisions are taken in a framework and policies are dependent of certain selected value. The simple fact of selecting a problem is based on values. Governments have a wide range of tools at their disposal. For example, in order to discourage smoking, they can information (advertising campaigns), they can tax, subsidize, regulate, they can set up agencies that address the problem. Although policies change over time, instruments have inertia. Also, the instruments can be influenced by what is considered legitimate or not and the legitimacy is linked to cultural factors. The instruments may also be depending on legal restrictions or international agreements. Policies must show internal consistency and vertical/horizontal coherence, but is not always the case, as sometimes governmental institutions or departments of the same institution may not well communicate. Planning is an important step in the process of health policies. Problem solving planning, program planning, resource allocation planning, standardization of working procedures. All these involve 3 dimensions: operational, tactical and strategic planning. (Blum H.L., 1974)

\section{Phases of the process of elaboration of public policies in health}

William Dunn (Dunn N.W., 2010, p.58) states that, sometimes, a certain policy can be first adopted, and then justified by returning to the agenda, where a problem is 
reformulated to justify public expectations. After Dunn, the process of public policy development has several phases and their characteristics: 1. Establishing the agenda. Issues are included in the public agenda and some problems are addressed with long expectations. 2. Policy formulation. Policy alternatives are formulated to solve a problem. These alternatives can take the form of enforcement orders, legal decisions. 3. Adopting the policies. A certain policy is adopted with the support of a legislative majority, the unanimity of the heads of an Agency, etc. 4. Implementation of the policies. Once adopted, the policy is completed by the administrative units that mobilize the financial and human resources to comply with their provisions. 5. Policy evaluation. It is established to what extent the executive agencies; the legislative agrees with the requirements of a policy and with the fulfillment of its objectives. 6. Adaptation of policies. The evaluation units report to the agencies responsible for formulating, adopting and implementing policies that there are elements that need to be adapted: defective written regulations, insufficient resources, inadequate training, etc. 7. Continuing (succession) of policies. The agencies responsible for evaluating policies together with those who develop policies recognize that there is no need for a policy because the problem is gone.

According to Mahon A. et al. (2009), the factors that are determining the policy strategies are consumerism, socio-demographic and economic changes, technological development, globalization etc. The role of the consumerism refers to a general increase in expectations and a reduction in confidence in institutions. Health care consumers are no longer passive patients. Citizens are more educated and informed nowadays, more critical and they expect quality services, for paid taxes. Increased population mobility and speed of travel. Socio-demographic changes refers to aging of the population and changing disease patterns, associated with age. Also, it refers to migrants of the population from conflict areas and migration of labor force. The technological development means advanced technologies: in biomedicine, genetics, pharmacology and imaging. There is also evolution of the concern related to the increase of the costs, the efficiency of the cost-results ratio.

Also, according to Mahon A. et al. (2009), there are several types of reaction in healthcare system reform. One type of reform is the open government. The main features of this type of government are transparency, accessibility, responsivity. Another type to reform is by increasing the performance of the public system. To achieve this objective, countries have adopted a series of managerial approaches that refer to budget, staff, institutional structures. Examples of institutional changes may be the creation of executive agencies, privatization or outsourcing of service provision. The quantity of information on performance is constantly increasing, and the problem concerns the quality and applicability of this information in improving policies. Also, management analysis and budget analysis are important. Other types of reaction are modernizing the structure of responsibility and control, reallocating financial resources and restructuring, using markettype mechanisms, modernizing employment in the public system

\section{Breaking the public monopoly}

Also, Mahon et al. (2009) shows that there are several common factors that underpin health policy responses since the 1980s. One of them is a move towards reforms 
inspired by rules, market principles, from models associated with public administration, to business models, talking about a new public management. It is about using the borrowed ideas from the market field in public sector management and breaking the public monopoly.

Efforts to reform and streamline public administration have been around for a long time, but it was only in the 1980s that they began to be put on the public agenda, along with criticisms of the welfare state. The emphasis was not on its administration and change but on how we can make public institutions' management more efficient and one of the most important changes was in the field of personnel management. It was found that the traditional systems of remuneration and evaluation of civil servants, including employees in the health system, which offer them the same award, regardless of performance, are not efficient and do not stimulate performance.

Regarding the management of state health organizations, the systems began to open for people with management experience and not necessarily with medical training or management concession to the private sphere. All these changes have the main purpose of introducing competitiveness between individuals in order to increase the efficiency. One of the criticisms frequently brought to classical public administration is that management rules and regulations (personnel, procurement, budget) prevent competent management from implementing its own qualities.

The new public management has brought an efficiency of the public system, but it has not brought all the advantages supported by the supporters of the public-private mix in administration.

Peters Guy (Peters G., 2000) talks about some limitations of the new public management: the intervention of the private sector in administration has determined the increase of the complexity of the distribution of services and the difficulty of controlling these services; modification of the traditional forms of responsibility and granting the managers of the main function of ensuring the performance in public management and autonomy in pursuing the organizational objectives, brought to a decrease of the mechanisms of responsibility that supposed the subordination of the public administrators to the objectives set by the elected ones; initially the management represented a closed career system to those from outside. Changing career structures has led to the loss of some of the public sector's organizational memory. Managers who manage public programs may only know to some extent the responsibilities and constraints of the public sector; the problem of coordination was emphasized, dividing the public administration into autonomous organizations and giving more and more power to their leaders.

Another factor that underpins health policies can be considered path dependence. It is about the continuity of public policies in the health field and other fields and the importance of the choices made in the past on the present decisions. The path dependence explains the stability of the options and the resistance to change. The mechanisms that determine an option are becoming more and more compelling as they register over a longer period. It involves investment costs, learning effects, coordination and anticipation capacity. The change involves investing in learning, the ability to 
predict new behaviors, changing expectations, organizational stress. On the one hand, the mandates of the elected are on a short earthquake, which makes them choose the less expensive solution from a political point of view. A completely new solution often presents immediate costs, for its implementation and learning, for long-term benefits and is therefore not chosen by politicians. (Pierson P., 2000)

\section{Uncertainty and limited rationality theory}

The theory of limited rationality (Richard B., in Bousagguet L, 2009) refers to the fact that the actors involved in the decision: individuals, groups, institutions, have certain preferences and adopt certain strategies of action according to them. The notion of deference applies to interests of various types: moral, but also material. Applying rationality implies that actors can anticipate and prioritize the consequences of their actions. The conditions for deciding are not certain, but risky. The consequences of the decision are anticipated by a distribution of objective or subjective probabilities, known as a range of estimates. However, the consequences are often quite unpredictable.

Zamfir (Zamfir C., 2005b) shows that uncertainty is part of any decision-making process. Uncertainty consists of cognitive elements (incompleteness of knowledge) and objectives (the ratio of quantity and quality of knowledge). Uncertainty means that there is no guarantee that the decision maker will identify the best solution, relative to the level of knowledge available to it. A source of uncertainty is the formulation of alternative solutions.

Generally, the state of uncertainty generates a state of tension in the decision-making system and causes it to oscillate between delaying or adopting a decision, continuing the decision-making process or returning.

Theory of the relevance of rational choice explains the degree of efficiency in the markets of health services. How can the efficiency of a health program be measured, especially the link between costs and benefits (quality of services)? What impact does the competition have on the market on medical professionalism, patient satisfaction, economic efficiency and access to health services. The followers of this theory use term such as expected utility, self-interest, strategic behavior, instrumental rationality. (Adrain C., 1998)

The theory of social opportunities elucidates the link between public policies and health. Cultural values, socio-political structures, individual behaviors shape the origins, processes, effects of health policies. Motivating people to participate in the political process, cultural values influence priorities.

Involvement of health policies: Instrumental rationality, efficiency, planning, concern for the long-term consequences of decisions. Universalism of the decisions against, local criteria. Impressive structures compared to the personalized structures at the local level in which there is a personalized doctor-patient relationship. Often the dominance of the principles of the market, of capitalism, against the social principles: see the market of medicines etc. There is the rise of differentiated functionalism. Each has its clear, socialized, stratified role in the system. The state is trying to divide the financial pie between the various branches. Although the nation-state holds the supremacy in 
implementing health policies, other bodies such as the EU, the World Bank, WHO intervene. Drug companies are often of international concern. Pressures from active groups such as people with disabilities, people of other ethnic groups, groups of patients, etc. can occur. Which groups most influence the decision-making process of health policy? Which groups have the most benefits and which groups have the least? How egalitarian, comprehensive the policies are? What variables explain the link between social stratification and health? why are some groups healthier than others? Those with a higher socio-economic status have better access to health everywhere. How can health policies reduce the gap? (Adrain C.F., 1998)

In European countries, after World War II, health became available to all citizens, from which the decrease of infant mortality and the increase of life expectancy. People with low incomes have also benefited from these programs. All people with high socio-economic status still benefit from the best health care. The increased access to specialists is the urban one. Therefore, those who receive the least benefits from the health system throughout the world are rural residents, urban poor, low-educated individuals, ethnic minorities, etc. Therefore, the increase of the access did not produce an equal state of health between different socio-economic groups. The most active participants in the policies are managers, administrators, professionals in the category of higher education, high incomes, organizational ties. Their policies influence social inequality

During the 1990s, keeping costs in place placed systems' priority on efficiency rather than equal access, equal treatment for similar health needs, and programs to achieve equalization of health in the population. Government officials have reduced services, increased taxes, copayments, deductibles, user fees. Most of these policies suffered from low income groups.

\section{Decisive systems with closed structures and open structures}

Social systems are oriented towards achieving their own ends and have their own selforganization. (Zamfir, 2005a) The functional requirement involves the active orientation of the system in order to create and maintain the conditions necessary for its proper functioning (survival and development), and the functional requirements give the finalist orientation of the system:

- Adapting - obtaining the facilities that are necessary for its operation

- Achieving the goals - mobilizing the energies to achieve the goals

- Integration of the parties into a harmonious whole

- The latency - regulating the internal tensions that come from the relationships between the actors

Decisive systems, depending on strategy, (Zamfir C, 2005b) may have closed or open cognitive structures. The closed ones have a defensive orientation: they maintain their rigid structure by informational isolation in relation to the environment. The open ones 
are flexible and change oriented and change their internal structure according to the information flows.

The power structure of the healthcare system in Romania is according to my evaluation rather of a closed type, characterized by several elements: a lack of evaluation of decisions in the short, medium and long term, a system of independent and inefficient evaluation indicators, defensive decisions, responsive to serious punctual problems that come back on the agenda, rigidity and politicization of structures

Institutionalization and reform take place in a context of structural and conjunctural factors: the arrival of a party / coalitions in power, the assumption of common interests by a group of actors, the finding of failure of previous measures. (Delpeuch T., Vigo C., in Bousagguet L et al, 2009). The crisis periods are characterized by an excessive investment in reforms, institutional ways of managing the crisis and legitimizing the policy. On the other hand, informational constraints influence institutional changes. Institutions have an inherited culture: practices, tacit codes of conduct, which are difficult to modify through deliberate action. On the other hand, structuring decisionmaking mechanisms limits the ability to reform. By questioning the unequal capacity of the Swedish, French and Swiss governments to build a national health system after 1945 , it is shown that a number of factors are involved: the presence of vetoes in parliament, the absence of the majority logy, the possibility of imposing the realization of referendums, the pressures exerted by the interest groups on the authorities to divert the reform projects. Reforms are therefore a combination of intentional and unintended changes, incremental and large-scale transformations.

In Romania, social policies are still reactive and offer ad-hoc solutions to specific crises, lack of strategic approach, do not rely on evidence, on social indicators, do not resort to monitoring and evaluation of current and previous programs.

Human resources in the sphere of social policies were often of poor quality, in the rural area were unqualified, poorly paid, named and controlled politically and at the peak, which is supposed to print a certain strategic vision, they were constantly changing, on political and political criteria. not of competence, increasing the effect of continuous change that generates inconsistency.

A health policy refers to innovation and change but it may also refer to maintaining the status quo. Those in power may cause change or prevent it, preventing certain topics from reaching the agenda and certain decisions being made. So not only observable decisions, but also non-decision making, must be analyzed. The state can be an instrument that represents the power of the citizens or it can be an instrument of maintaining the economic interest groups antithetical to the social interest. Very important is the way in which the role of the state and the history of the country is socially, economically and politically contextualized.

Power is exercised not only in conflict situations between interest groups but also in preventing the occurrence of these conflicts. Some rulers can manipulate and model the desires, needs, values, norms of behavior of the population, so that it sees only one side of the problem and does not want something alternative. This can be achieved through the domination of some groups in society, through mass media, etc. Thus, observable 
or latent conflicts may arise that derive from the contradiction between the interests of those in power and the interests of those excluded from power.

Does the question arise what is the nature of state power in modern society as the main provider and the main buyer of health services? Is the role of regulator of the state expanding or on the contrary at present? What is the role of the private market? Has the private market become stronger, through the tendency of decentralization and the public-private mix in the provision of services?

The case of the reform of the health system in Poland is edifying for the obstacles that may be encountered in the way of reform. In 1990, Poland decided to start privatizing the system. In the same year, the law of care units was adopted, according to which the ambulatory units were divided into two structures: (Kozierkiewicz, A., 2011) a public one, but an autonomous one (SPZOZ) and a nonpublic one (NZOZ), managed by private bodies, including foundations. The system before 1989, owned by the state, was considered inefficient. SPZOZ had autonomy in management and are registered in the legal and national register having a legal status as companies and foundations, but they are protected from bankruptcy through state intervention, regulated since 1990. In the following years, through evaluation, it was observed that this mechanism of State intervention protected, but at the same time it made some activities more difficult, such as acquisitions, and the SPZOZ managers felt protected by the state, spending much more than was allocated to them. Therefore, part of SPZOZ began to accumulate large deficits (in 2008 they amounted to 1, 5 billion euros). The decision that was taken was privatization, most of the outpatient units being transformed into NZOZ today. Private providers are integrated into the publicly regulated system. The privatization was not correlated with the sale of the properties, which are still owned by the local administration, and the spaces are rented for companies, whose personnel come from the former SPZOZ employees. In the 2000 s, the decision was made to tender the hospitals. However, the population was reluctant to this change. In general, privatization as a principle was accompanied by fears. Against the background of population fears, the opposition has vehemently raised and attacked this kind of reform. As a result, the government undertook the reform, despite the small support of the voters and strongly attacked by the opposition, and only part of the hospitals were privatized. The indicators analyzed following the privatization showed an improvement both on the financial side and on the management side of the privatized ones. The government regulated financial aid measures for privatized hospitals to support them: special lines of credit for investments, financial aid through receivables.

\section{Opportunity windows}

The window of opportunity was theorized by John W. Kingdon in the 1980s. The window is a metaphor that compares setting the agenda with launching a space mission, which must be launched during the window, when the currents meet. There are three currents (Ravinet Pauline, in Bousagguet L et al., 2009): 1. Current problems. There is talk of a problem when people are convinced that something can be done to improve the situation. Three mechanisms allow problem situations to become transparent: indicators, shock events, feedback as a result of an assessment. 2. Current solutions. 
Numerous competing alternatives are circulating within the solutions. These solutions are not initially designed to solve problems, they are floating in search of problems to be encountered or events. The alternatives must be technically feasible, compatible with the dominant values. 3. The political current. The current includes public opinion and its sudden changes, electoral politics, changes, altercations at the level of government and administration, the actions of pressure groups.

The political context becomes favorable for a problematic issue. An alternative can be grafted onto a problem, generally not being the best solution. These windows of opportunity that open when the currents meet is then closed again when the actors fail to get in on the action, when the events that caused the window to open are no longer current or there is simply no alternative available.

Regarding how predictable the window is to open, Kingdon (in Bousagguet L., 2009) identifies two types of predictability criteria: 1 . regarding the problem and its access to the agenda. If a problem is specific, it can be taken up quickly by specialists. If a problem is known and widespread, it will reach the address book faster; 2. regarding the political context. In certain periods of political change, the agenda is much more open. A window has more chances to open when the mandate given to the government is more important or historical alternations.

The period immediately following the moment of December 1989, in Romania or the moment of the change of the law of the health system from 1996 through the transition to health insurance or Collective accident (2015) were windows of opportunity for the healthcare system that were missed.

\section{Sectoriality and intersectoriality of public action}

Cătălin Zamfir (Zamfir, 2005a, p 123) shows that departmentalization is an endemic pathology of the subsystems. Subsystems tend to become autonomous to the extent that their sectoral goals are set above global goals. There are two types of explanations: the holistic explanation that the subsystems do not have the vision of the overall objective and focuses on the goals delegated to them and the individualistic explanation that the subsystem members are rewarded for meeting their delegated sub-goal. Thus, they put the objectives of the subsystem above those of the system.

The sectorality of public action (Pierre Muller, in Bousagguet L et al. 2009) states that it is difficult to release a sectoral logic in defining the problems of public action. The sectorization is related to the realization of an expertise in the field. The experts claim a monopoly of expertise that translates into a monopoly of institutional specialization. So, on the one hand, public action cannot be freed from sectorization, on the other hand, it should consider the global nature of the problems. Overcoming the sectoriality can be done by replacing it with intersectoral strategies, determining the collaboration of the actors from different sectors. In this way, cross-sectoral policies can be developed, which do not identify with a sector, but which integrate into all the sectors concerned. 
Health is closely linked to the concept of quality of life. Starting from this vision, the offer of health services must be combined with social assistance, psychological counseling, services at the patient's home or services for people with disabilities or people with other types of medical and social problems at the same time. The social policies in the health field must therefore be efficiently combined with other types of social policy for the most adequate investment in the recovery of the human capital of the respective community.

Secondly, there is a need for a relevant analysis by the decision makers of the social dimensions that correlate the optimal social model for the assurance of a healthy human capital, in order to be able to make long-term forecasts and to know at what point to act for to achieve the desired results.

In the analysis of the policies aimed at population health, we must not limit ourselves to the analysis of the formal institutions of the health system but to analyze all the policies that affect the health and well-being of the population:

At a general analytical level, health policy can be conceptualized in terms of macro or micro social processes. At the macro level, macro social structures are included in the analysis: the state, the market, the economic and legislative network, the formal institutions that ensure the provision of services such as the national health system. At the micro level, the analysis refers to the impact of policies on the level of professionals in the system and on the level of service consumers.

\section{Conclusions}

In the last 15 years, the provision of health services expanded, and the administrative structures gradually expanded. Public institutions assumed responsibilities that private institutions had before the war: families, the church, mutual aid groups. The expenses increased with the health, the benefits became more generous, the urban and rural population accessed the services, various marginalized groups gained access to health: the poor, the elderly, etc. The coverage of the population with services increased as well as the scope and diversity of services.

The 1970s brought cuts in the costs allocated to health due to the welfare state crisis. In the early 1980s, local government began to gain more scope in some developed European countries: the Canadian provinces, the German provinces, the states in America, the cantons in Sweden. A decentralization process has begun. The regions and the central government have come to have similar responsibilities. Health expenditure growth did not increase as rapidly as in 1960-1980. The programs started to be austerity. The policy has become less inclusive and generous. Although a similar pattern could emerge, however, there were differences between Japan, the Western countries, and North America. The United States had a strategy that included less inclusive, less generous and less egalitarian programs. Other nations, such as England or the Netherlands, have introduced a competition policy, yet citizens have equal access to services. Sweden relied on reduced privatization. The Canadian government has decentralized services to regions. Even with the reduced benefits, services have remained accessible to more citizens than in the US. Germany has decentralized, offering generous but uneven services. France had 
the reputation of a cohesive, centralized state, yet the regionalization of authority over health problems was achieved. Private hospitals and private doctors still exercise considerable autonomy over tight government control.

By decentralizing policies and bringing them closer to citizens, returning to the community, managing sectoral fragmentation will be less difficult. Decentralization generally refers to the transfer of a certain form of power or responsibility from the level of central authority to local or regional levels. According to Shafritz, (Shafritz J.M., 1998), decentralization can take two forms: devolution and deconcentration. Devolution involves a transfer of political power and decision-making power. Deconcentration is the transfer of predominantly administrative functions. The most common argument for devolution is the proximity of local authorities to the population, but in practice it has been found that the real influence of the individual is rather determined by the local structure of power. On the other hand, with the increase of the power of the devolved organisms, the power of the central organisms can also increase. From the functional point of view, the devolution can be territorial (the devolved body takes over all the functions of the central body from the point of view of the decision) or functionally specialized (there is no territorial paternal, the devolution being to specialized organisms).

\section{References}

Adrain C. F. (1998). Public health policies and social inequalities, London: MacMillan Press Ltd

Arcaya M., Arcaya A. and Subramanian S. V. (2015). Inequalities in health: definitions, concepts, and theories, Glob Health Action. doi: 10.3402/gha.v8.27106

Boussaguet L., Jacquot S. and Ravinet P. (2009) Diç̧ionar de politici publice, Iaşi: Editura Polirom

Blum H.L. (1974). Planning for Health: Development and Aplication of Social Change Theory, New York: Human Science Press

Chisholm D. and Evans. David B. (2010) Improving health system efficiency as a means of moving towards universal coverage World Health Report, Background Paper, no 28

Delpeuch T., Vigo C., in Bousagguet L et al. (2009). Dicționar de politici publice, Iaşi: Editura Polirom

Dunn N. W. (2010). Analiz̧a politicilor publice. O introducere, Iaşi: Editura Polirom

Kozierkiewicz A. (2011). Will legal restructuring affect the real economy of hospitals? in Health Policy Deveploment in Eurobealth, 15(2)

Mahon A, Walshe K, Chambers N. (2009). A Reader in Health Policy and Management, Open University Press

Peters B. G. (2000). The Future of Governing, University Press of Kansas.

Pierson, P. (2000). Path Dependence, Increasing Return and the Study of Politics, in American Political Science Review, 94

Pierre M., in Bousagguet L et al. (2009) Diç̧ionar de politici publice, Iaşi: Editura Polirom

Ravinet P., in Bousagguet L et al. (2009) Diç̧ionar de politici publice, Iaşi: Editura Polirom

Shafritz J. (1998) International Encyclopedia of Public Policy and Adminitration, Colorado: Westview Boulder,

Zamfir C. (2005a) Spre o paradigmă a gândirii sociologice, Iasi: Polirom, Iaşi, p. 123

Zamfir, C. (2005b) Incertitudinea: o perspectivă psihosociologică, Bucureşti: Editura economică 